\title{
Dynamic Life Insurance Premium-to-GDP Under Inflation Risk: Comparing Indonesia and the Philippines
}

\author{
Debrina Vita Ferezagia ${ }^{1 *}$ \\ ${ }^{1}$ Insurance Laboratory, Vocational Education Program, \\ Universitas Indonesia \\ *Email: debrinaferezagiaa@gmail.com
}

\begin{abstract}
This study analyzes the growth of life insurance premiums in the gross domestic product (GDP) under inflation risk and compares this growth for Indonesia and Philippines using life insurance premiums-to-GDP and inflation data from 1990 to 2015. The sample was assembled through proportional sampling, and the data analysis consisted of descriptive statistics and a correlation test. Based on time-series charts, life insurance premiums in Indonesia's GDP are found to be lower than those of the Philippines, although this has fluctuated over the last 25 years. The correlation test results show that inflation has a negative effect on life insurance premiums. In the Philippines, inflation risks have an effect on life insurance premiums, with a considerable correlation value of -0.6837 . In other words, rising inflation in the Philippines significantly reduces the value of life insurance premiums in GDP. This is different from Indonesia, where there is no significant influence of inflation on the life insurance premium with a correlation value of -0.2531 . This is because the penetration of insurance (as percent premium to GDP) in Indonesian society is relatively small compared with the Philippines.
\end{abstract}

Keywords: premium, life insurance, gross domestic product

\section{Introduction}

Revolutionary changes 2.0-4.0 signaled Indonesia's entry into the digital era, where all members of the society can access information quickly. Similarly, the life insurance industry in Indonesia has made use of technology, especially information technology, to develop the market. Life insurance companies compete to create innovative life insurance products that fit the needs of their target market, making it possible for all consumers to choose relevant life insurance products.

Bilateral written contractual relationship on life insurance based on which the insurer promises to pay some money, either in whole or by installment. The risk covered by this insurance is the end of a person during a specified period (Emangholipour, Arab, \& Mohajerzadeh, 2017). On current life insurance, claims are paid at the end of a year after death, according to police agreement. Many life insurance products are marketed with investment and growing rapidly; those products are much in demand by consumers in Indonesia.

The growing insurance industry is expected to contribute to the gross domestic product (GDP). Prior research conducted by Webb, Martin, and Skipper (2002) and Boon (2005) concluded that the insurance industry contributes to economic development in "supply-leading." The importance of insurance on economic development is also reflected in the growth of insurance premiums, insurance assets/funds in the GDP, and as total financial assets (Chau, Khin, \& Meng, 2016).

In monetary economics, inflation risk is the most critical economic risk that consumers and investors face. Each consumer and investor must ensure the future security of his or her financial condition. Likewise, consumers and investors provide their financial situation in financing expenses in retirement. Liabilities from pension funds and endowments will increase along with inflation, which continues to fluctuate. Inflation over the last ten years; however, economic observers have recently predicted the inflation rate in coming years (Bekaert \& Wang, 2010).

Pirvu and Zhang (2012) and Kwak and Lim (2014) analyzed the impact of each stochastic market price on life insurance demand. Based on existing research, inflation also has a significant influence on investors. In this connection, if inflation is much higher than at the acquisition of an investment, then the investment will be canceled and vice-versa. Based on this background, the authors will analyze the effect that inflation risk has on life insurance premiums to GDP. 


\section{Literature Review}

\subsection{Previous research}

A similar study was conducted on the UK insurance industry (the largest in Europe) by Ward and Zurbruegg (2000). The data used is a tremendous time coherence in 1971-2003. Their results suggest a supplyleading pattern in which it can be concluded that insurance premiums affect GDP. The literature suggests that the leading-supplying hypothesis is valid. In certain cases, this hypothesis has been validly tested in Canada, Italy, and Japan. Boon (2005) argued that the causality relationship has a tendency that varies according to the indicators used. This study shows a significant influence on the development of insurance and economic growth, making it necessary to study further from all aspects. Findings from the literature review indicate that various insurance variables promote economic growth.

Insurance contributes to economic growth through an insurance function that acts as an intermediary and provides support to other financial partners such as banks and the stock market. Skipper (1997) outlined the ways in which insurance companies act as intermediaries in promoting economic growth: (1) improving financial stability, (2) facilitating trade and commerce, (3) mobilizing domestic savings, (4) allowing different risks to be managed more efficiently, thus encouraging the accumulation of new capital, (5) supporting more efficient allocation of domestic investment, and (6) helping reduce losses. Therefore, financial stability is essential for the continuation of economic growth. Insurance offers protection to consumers, households, and companies from unexpected losses and thereby creates a more stable financial condition.

Insurance could help generate sufficient funds for state investment as an expansion of business investment, thereby contributing to economic growth. Insurance allows for various risks to be managed more efficiently. With low-risk exposures, household and business financial conditions will be stronger. Insurance companies also can be institutional investors in financial markets, such as the stock market. Haiss and Sümegi (2008) argued that insurance has a major role in economic growth as a function of financial decency. Functions of the financial sector are as follows: (1) to increase the screening of fund-raisers or monitor beneficiaries, thereby increasing the allocation of resources, (2) to mobilize savings, (3) to reduce capital costs through an economic scale, and (4) to provide risk management and liquidity (Wachtel, 2001). This means that the insurance industry can promote long-term domestic savings through life insurance products. Zou and Adams (2006) conducted a recent study that highlights the relevance of insurance in promoting economic growth using overall premium income in the insurance industry as well as for various types of insurance products.

Another study was also conducted in Singapore by Boon (2005) who investigated the relationship between financial development and economic growth using data from 1985 to 2002. In this study, insurance is one component of the financial harvest of hitches from banks and stocks. Market development is represented by total insurance funds. The results show that the long-term causality effect of total insurance funds on real per capita GDP is matched by seasonal influences. This generates both short- and long-term effects on the total insurance fund to form gross fixed capital per capita. These findings significantly support the influence of insurance on economic growth. It also provides the benefits of financial data and varying relationships with various indicators.

\subsection{Correlation analysis}

Correlation analysis is a statistical method used to study the strength of relationships between variables. Correlation between two variables is when a systematic change in one variable results in other systematic changes. Variables can change together over period. If any correlation is generated, then, it can be either positive or negative, depending on the numerical value being measured (Lee Rodgers \& Nicewander, 1988). Positive correlations exist if the variable increases with the other variables. This means that the high numerical value of one variable corresponds to the value of high numeric of the other. A negative correlation exists if one variable decreases as the other increases, that is, the high numeric value of one variable corresponds to a low value of the other.

Pearson product-moment correlation measures correlation on a scale between +1 and -1 . The strongest positive correlation is shown by +1 and the strongest negative correlation is -1 . Therefore, the closer the coefficient is to one of these numbers the stronger the correlation of the data it represents (a value of 0 meaning no correlation) (Lee Rodgers \& Nicewander, 1988).

Pearson's $r$ correlation is the most widely used correlation statistic to measure the relationship degree between linearly related variables. Pearson's correlation is used to measure the relationship level between the two. The following formula is used to calculate Pearson's correlation $r$ (Lee Rodgers \& Nicewander, 1988): 


$$
\gamma=\frac{\mathrm{N} \sum \mathrm{xy}-\sum(\mathrm{x})(\mathrm{y})}{\sqrt{\left.N \sum x^{2}-\sum\left(x^{2}\right)\right]\left[N \sum y^{2}-\sum\left(y^{2}\right)\right]}}
$$

$r=$ Pearson's $r$ correlation coefficient

$\mathrm{N}=$ number of observations

$\sum x y=$ sum of the products of paired scores

$\sum \mathrm{x}=$ sum of $x$ scores

$\sum \mathrm{y}=$ sum of $y$ scores

$\sum \mathrm{x}^{2}=$ sum of squared $x$ scores

$\sum \mathrm{y}^{2}=$ sum of squared $y$ scores

\section{Methodology}

The data used in this research is time-series data spanning 25 years (1990-2015) from Indonesia and the Philippines. The data were obtained from annual data published in FRED Economic Data. The variables used are inflation rate and the ratio premium life insurance-to-GDP. This research used a descriptive and comparative approach. Descriptive statistics include time-series graphs and a correlation analysis is used to examine the relationship between the variables. Scatter diagrams are used to help describe the type of relationship between the two variables.

\section{Results}

\subsection{Life insurance premium-to-GDP}

The insurance industry in Indonesia is growing rapidly, with modernization and increasingly fierce competition in the industry market. Life insurance accounted for $46 \%$ of total premiums in 2014, with most focused on investment products. Positive growth is expected to continue in 2020. The impact of insurance on economic development is reflected in the growth of insurance premiums as a share of GDP as well as total financial assets. Figure 3.1 graphs the percentage premium life insurances in Indonesia and the Philippines from 1990 to 2015, and shows that the growth of premiums to GDP continues to increase. In Indonesia, there is a decline from 2010 to 2015, which was also experienced by the Philippines from 2006 to 2008.

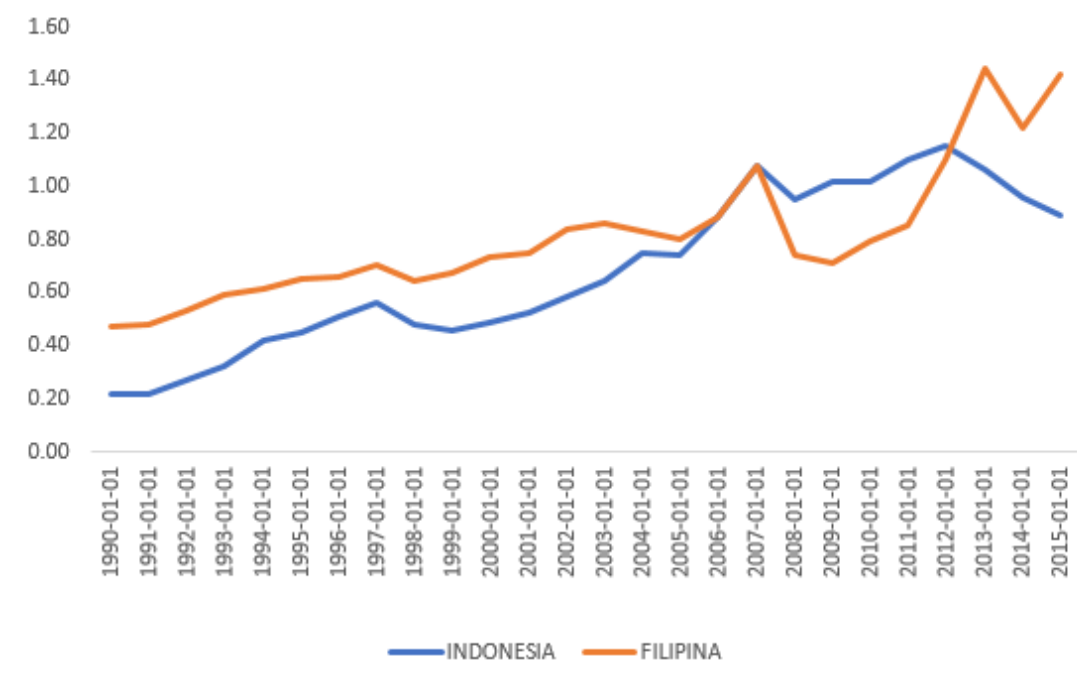

Figure 4.1 Life insurance premium-to-GDP (1990-2015)

\subsection{Inflation risk}

An increasing year-on-year inflation trend is observed in the time-series graph in Figure 3.2, with some fluctuation in both countries during 1990-2015. The highest inflation in Indonesia occurred in $1998(58.4 \%)$ and spurned a monetary crisis in Indonesia. After that, the economic condition of 
Indonesia, especially the financial sector, consolidated in many ways to regulate the sector and create more stability. In the Philippines, the highest inflation spike occurred in 1991, with a rate of $19.3 \%$. The lowest inflation periods occurred in Indonesia in 2000 (3.7\%) and in the Philippines in 2015 $(1.4 \%)$.

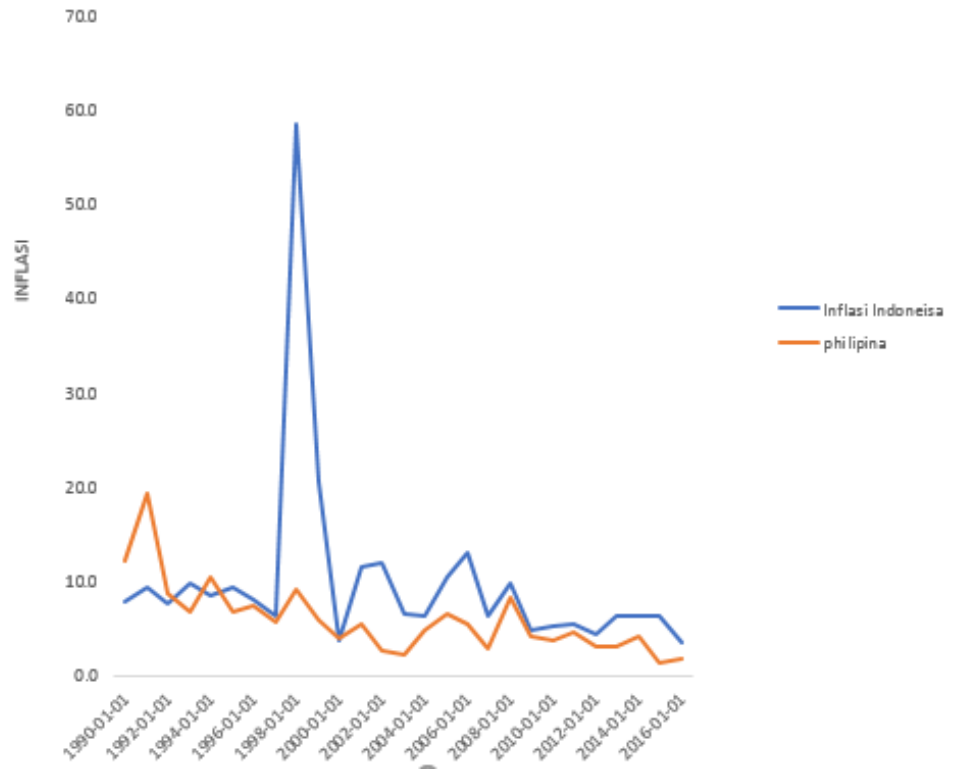

Figure 4.2 Inflation rates in Indonesia and Philippines (1990-2015)

\subsection{Insurance under inflation risk}

Life insurance premiums are expected to continue to develop positively; therefore, the inflation risk can be analyzed by looking at the relationship between the two variables. Figures 3.3 and 3.4 show the relationship between percent life insurance premium-to-GDP with inflation in the Philippines and Indonesia. In the Philippines, the scatter plot has a negative linear trend while Indonesia has a random pattern (no trend).

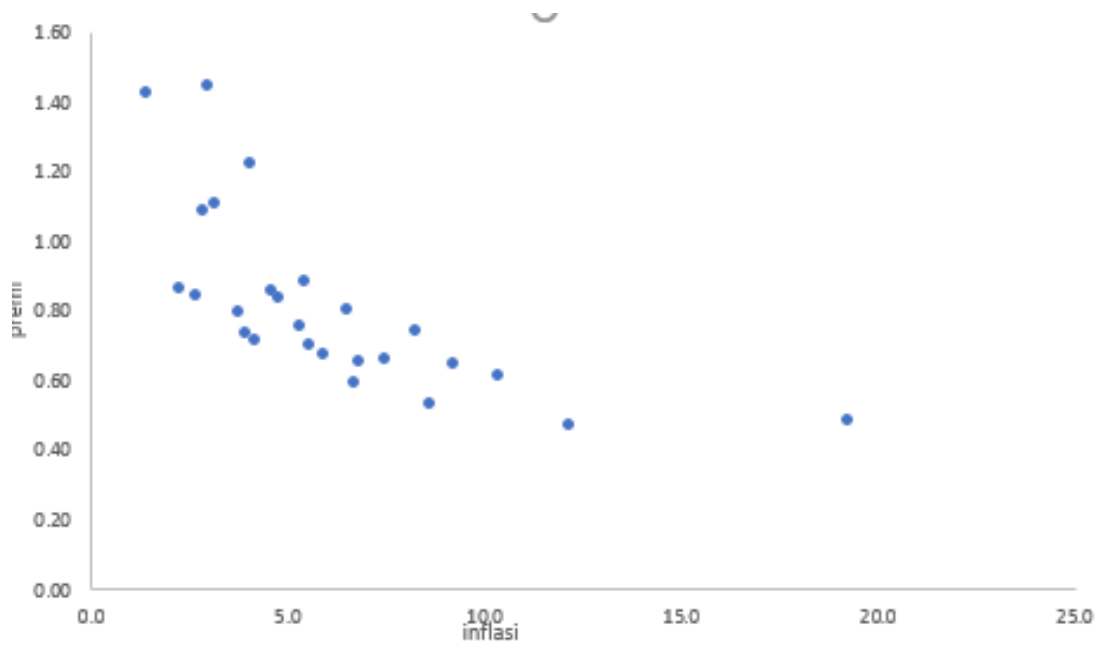

Figure 4.3 Life insurance premium under inflation risk in the Philippines 


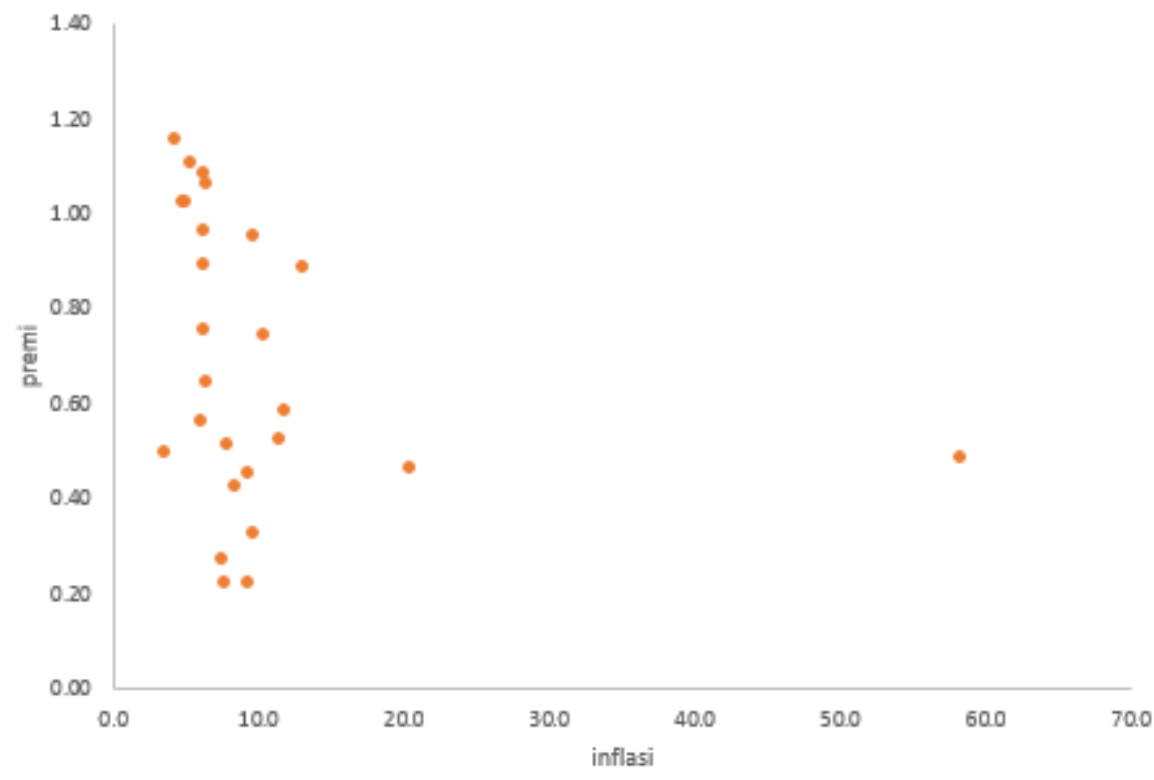

Figure 4.4 Life insurance premium under inflation risk in Indonesia

The hypothesis population correlation coefficients are:

$\mathrm{H}_{0}: \rho=0$

$\mathrm{H}_{1}: \rho \neq 0$

Correlation analysis shows the closeness of the relationship between inflation risk and life premium. The correlation between inflation and life premium insurance in Indonesia is -0.2531 ( $p$-value $=$ 0.23). In other words, there is no significant relationship between premium life insurance and inflation. In the Philippines, however, the correlation between premium life insurance and inflation is -0.6937 ( $p$-value $=0.000$ ). It can be shown that there is a significant relationship between premium and inflation. In the Philippines, experienced inflation it will reduce the presentation of insurance premiums against GDP.

\section{Discussion}

There is an interesting phenomenon happening in Indonesia: inflation risk does not influence life insurance premiums. Indonesia's low insurance penetration is estimated to reach $1.1 \%$ for life insurance. This is different from the Philippines, where the penetration rate is about 3\%. The low level of insurance penetration is one of the factors causing no relationship between inflation and life insurance premium. The low level of insurance penetration in Indonesia is due to lack of knowledge/literacy and public awareness of the concept of insurance benefits. Another cause is still at least the products that can answer the needs of all levels of society. 
The number of agents/marketing personnel and insurance experts in Indonesia is still minimal. Efforts are being made to increase literacy by extending education and socialization regarding the role of insurance to improve the welfare of the community. The insurers need to work hard to educate the public about the importance of insurance. Penetration can also be done by extending insurance products to community groups that have not previously used insurance, such as fishermen, farmers, and small entrepreneurs. In addition to insurance agents that directly deal with the community, the media also become the best means of insurance education. Socialization through mass media can be done through print media, electronic, and online.

National insurance penetration can also be increased by encouraging digital insurance products that are distributed or distributed through digital media. Digital insurance is an inevitable demand of the times. Currently, many insurance companies are utilizing digital technology to offer products, complete policy applications, policy shipments, and recruit agents. All activities can be completed online via the internet using either a personal computer or smartphone. The amount of digital insurance business in Indonesia is also supported by the increasing penetration of the internet and smartphones.

Indonesia is the sixth largest internet user in the world. Based on 2016 figures, internet users in Indonesia may number as many as 132.7 million people or about $51.8 \%$ of the total population of 256.2 million. That number will continue to increase. However, behind the vast market potential, the insurance industry still needs regulatory support, especially for regulating digital insurance. Rules for digital insurance are required in line with the shifting of insurance business trends from conventional to digital systems following the rapidly and dynamically changing information technology environment. In addition to regulating the behavior of insurance industry players, the rules must also protect customers.

\section{Conclusion}

Based on the results and discussion, insurance penetration in Indonesia is still low when compared with the Philippines. Theory suggests that the inflation rate is very influential on insurance premiums; however, this does not appear to be the case in Indonesia, as the results of this study show, whereas insurance premiums are greatly affected by inflation in the Philippines.

\section{Acknowledgment}

The researcher would like to thank the insurance lab at Universitas Indonesia Vocational education for supporting this research. 


\section{References}

Adams, M. J., Andersson, J., Andersson, L.-F., \& Lindmark, M. (2009). Commercial banking, insurance and economic growth in Sweden between 1830 and 1998. Accounting, Business \& Financial History, 19(1), 21-38.

Bekaert, G., \& Wang, X. (2010). Inflation risk and the inflation risk premium. Economic Policy, 25(64), 755806.

Boon, T. K. (2005). Do commercial banks, the stock market and insurance market promote economic growth? An analysis of the Singapore economy. Singapore: Nanyang Technological University.

Chau, H. W., Khin, A. A., \& Meng, A. T. G. (2016). Public expenditure and economic growth in Malaysia. 3rd International Conference on accounting Studies (ICAS). Kedah, Malaysia.

Emamgholipour, S., Arab, M., \& Mohajerzadeh, Z. (2017). Life insurance demand: Middle East and North Africa. International Journal of Social Economics, 44(4), 521-529. Retrieved from https://remotelib.ui.ac.id:2078/docview/1880341410?accountid=17242

Haiss, P. R., \& Sümegi, K. (2008). The relationship of insurance and economic growth: A theoretical and empirical analysis. Empirica, Journal of Applied Economics and Economic Policy, 35(4), 405-431.

Kwak, M., \& Lim, B. H. (2014). Optimal portfolio selection with life insurance under inflation risk. Journal of Banking and Finance, 46, 59-71.

Lee Rodgers, J., \& Nicewander, W. A. (1988). Thirteen ways to look at the correlation coefficient. The American Statistician, 42(1), 59-66.

Pirvu, T. A., \& Zhang, H. (2012). Optimal investment, consumption and life insurance under mean-reverting returns: The complete market solution. Insurance: Mathematics and Economics, 51(2), 303-309.

Skipper, H. D. (1997). Foreign insurers in emerging markets: Issues and concerns. Washington, DC: International Insurance Foundation.

Wachtel, P. (2001). Growth and finance: What do we know and how do we know it? International Finance, $4(3), 335-362$.

Ward, D., \& R. Zurbruegg, R. (2000). Does insurance promote economic growth-evidence from OECD countries. Journal of Risk and Insurance, 67, 489-506.

Webb, I., Martin, G., \& Skipper, H. (2017). The effect of banking and insurance on the growth of capital and output. Georgia State University, Atlanta: Center for Risk Management and Insurance.

Zou, H., \& Adams, M. B. (2006). The corporate purchase of property insurance: Chinese evidence. Journal of Financial Intermediation, 15(2), 165-196. 